\title{
Exploring natural killer cell immunology as a therapeutic strategy in lung cancer
}

\author{
Jonas B. Hess ${ }^{1,2}$, Kate D. Sutherland ${ }^{1,2}$, Sarah A. Best ${ }^{1,2}$ \\ ${ }^{1}$ ACRF Cancer Biology and Stem Cell Division, The Walter and Eliza Hall Institute of Medical Research, 1G Royal Parade, Parkville, Victoria, \\ Australia; ${ }^{2}$ Department of Medical Biology, The University of Melbourne, Parkville, Victoria, Australia \\ Contributions: (I) Conception and design: All authors; (II) Administrative support: KD Sutherland; (III) Provision of study materials or patients: None; \\ (IV) Collection and assembly of data: JB Hess; (V) Data analysis and interpretation: None; (VI) Manuscript writing: All authors; (VII) Final approval \\ of manuscript: All authors. \\ Correspondence to: Kate D. Sutherland, PhD; Sarah A. Best, PhD. The Walter and Eliza Hall Institute of Medical Research, 1G Royal Parade, \\ Parkville, Victoria 3052, Australia. Email: sutherland.k@wehi.edu.au; best@wehi.edu.au.
}

\begin{abstract}
Cytotoxic immune cells are key in the control of tumor development and progression. Natural killer (NK) cells are the cytotoxic arm of the innate immune system with the capability to kill tumor cells and surveil tumor cell dissemination. As such, the interest in harnessing NK cells in tumor control is increasing in many solid tumor types, including lung cancer. Here, we review the pre-clinical models used to unveil the role of NK cells in immunosurveillance of solid tumors and highlight measures to enhance NK cell activity. Importantly, the development of NK immunotherapy is rapidly evolving. Enhancing the NK cell response can be achieved using two broad modalities: enhancing endogenous NK cell activity, or performing adoptive transfer of pre-activated NK cells to patients. Numerous clinical trials are evaluating the efficacy of NK cell immunotherapy in isolation or in combination with standard treatments, with encouraging initial results. Pre-clinical studies and early phase clinical trials suggest that patients with solid tumors, including lung cancer, have the potential to benefit from recent developments in NK cell immunotherapy.
\end{abstract}

Keywords: Natural killer cells (NK cells); immunosurveillance; lung cancer

Submitted Jun 19, 2020. Accepted for publication Oct 19, 2020.

doi: $10.21037 /$ tlcr-20-765

View this article at: http://dx.doi.org/10.21037/tlcr-20-765

Natural killer (NK) cells, the cytotoxic component of the innate immune system, were named following the observation that they could kill tumor cells in vitro over thirty years ago (1). Now, in the age of immunotherapy, NK cells have re-emerged as a therapeutic strategy that can be harnessed for tumor cell control, an interest reflected by a substantial increase in the number of publications in this field (Figure 1A). Indeed, the therapeutic weaponization of NK cells is mature in solid tumors such as melanoma, however their utilization is emerging in lung and burgeoning in indications such as pancreatic cancer (Figure $1 B$ ). In this review, we interrogate why NK cells are a key cytotoxic immune mediator in controlling the dissemination of solid tumors. We explore NK cell research beyond the lung cancer field, that is currently investigating enhanced NK cell cytotoxicity as an immunotherapeutic approach. These insights will enable us to strategize the key elements of NK cell therapy, which may fast-track their implementation in the treatment of lung cancer.

\section{NK cells}

NK cells are lymphocytes of the innate immune system, primarily functioning as first responders to stressed cells. Functional human NK cells are identified by flow cytometry as $\mathrm{CD}^{-} \mathrm{CD} 56^{+}$and are categorized as cytotoxic $\left(\mathrm{CD} 56^{\mathrm{dim}} \mathrm{CD} 16^{+}\right)$or cytokine producing $\left(\mathrm{CD} 56^{\text {bright }} \mathrm{CD} 16^{-}\right)$ (2-5). They can directly induce target cell death through 

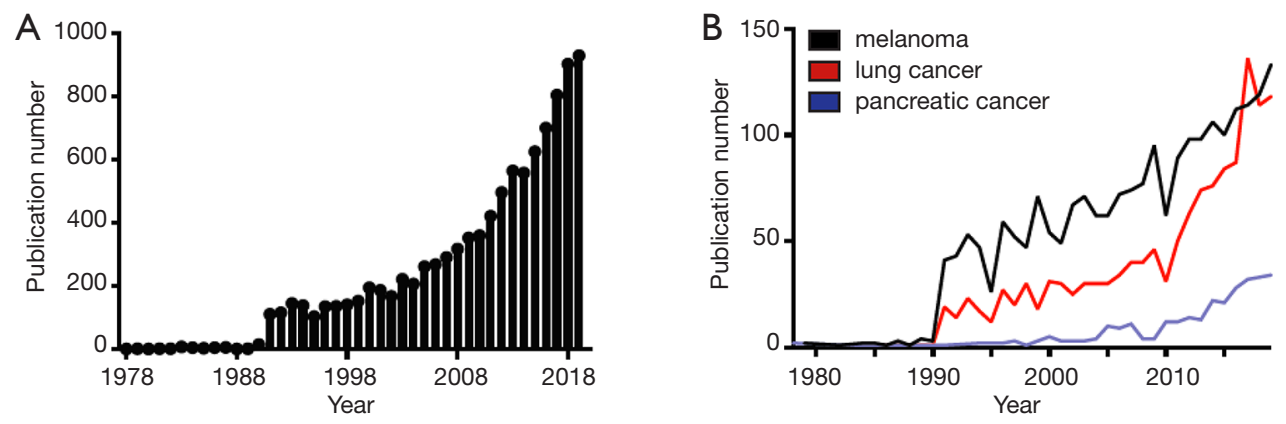

Figure 1 NK cell publication rate. (A) Publications describing 'NK cells' and 'cancer' since the initial discovery of NK cells in 1978. (B) Publications of 'NK cells' and melanoma (black), lung cancer (red) or pancreatic cancer (purple) since 1978. Data sourced from Web of Science.

the secretion of the pore forming molecules Perforin and Granzyme B (6) and indirectly induce apoptosis through the release of tumor necrosis factor- $\alpha(\mathrm{TNF}-\alpha)$ and Fas cell surface death receptor (FAS) ligand $(7,8)$. Moreover, NK cells play a broad immunomodulatory role through the secretion of cytokines, interleukins and interferons to mobilize the innate and adaptive immune response to the site of infection or disease (9-12).

NK cells play an important role in both the circulation and as resident cells in tissues. Their crucial function in barrier immunity is reflected by the recurrent infection and inflammation observed in the absence of NK cells $(13,14)$. Increased numbers of NK cells reside in tissues at the interphase between the body and the environment (15), with a high number of tissue resident NK (trNK) cells in the lungs (16). The large trNK cell population are reliant on cytokines, such as Interleukin 15 (IL-15) for their survival and development, which is secreted by bronchiolar epithelial cells in the lung (17). Unlike the majority of trNK cells, NK cells that reside in the lung are predominantly in the cytokine producing state $(18,19)$, likely due to prolonged IL-15 exposure $(20,21)$. Therefore, the trNK cells that reside in the lung are a key cytokineproducing compartment in the immune microenvironment contributing to immunosurveillance of the lung.

The cytotoxic activity of NK cells is dictated by a balance between activating and inhibitory signals, both in the form of ligands present on the interacting cell, or cytokines in the surrounding milieu (22). This activity primarily centers on the recognition of self through Major Histocompatibility Complex Class-I (MHC-I; mouse) or Human Leukocyte Antigen (HLA; human), which are ubiquitously expressed on all healthy tissue (23). Expression of MHC-I on healthy cells confers an inhibitory signal to NK cells via specific receptors. In humans, HLA are detected by receptors such as the killer immunoglobulin-like receptors (KIRs) and leukocyte immunoglobulin-like receptors (LILRs), while in mice MHC-I is detected by the family of c-type lectins (Ly49), whereby engagement of these receptors inhibits a cytotoxic response (24). Consequently, the lack of MHC-I on the cell surface therefore signals NK cell activation and induces a cytotoxic response (Figure 2). Therefore in cancer cells, the downregulation of MHC-I, a welldescribed mechanism of cytotoxic $\mathrm{T}$ cell evasion, results in the induction of the NK cell response (25). In addition to the absence of MHC-I, activation of the NK cell cytotoxic response includes a number of ligand interactions $(26,27)$. Primary activating receptors include Natural Killer group 2D (NKG2D) and recognize MHC-I-related proteins expressed on stressed cells [MHC-I chain related protein $\mathrm{A}$ and B (MICA/MICB) and UL16 binding proteins 1-6 (ULPB1-6); human. H60, murine UL16-binding proteinlike transcript (Mult1) and retinoic acid early inducible 1 (Rae1); mouse] (28). Additionally, the natural cytotoxicity receptor (NCR) family, including NKp30, NKp44 and NKp46, react to a broad spectrum of ligands inducing NK cell activation $(9,26,27)$. Taken together, the activation of NK cells is a complex balance of inhibitory and activating signals to initiate a cytotoxic response to stressed cells.

\section{Cancer surveillance}

The ability of NK cells to target stressed cells plays an important role in the surveillance of tumor initiation and disseminating tumor cells (29). This is evident in humans where increased cancer prevalence is correlated with 


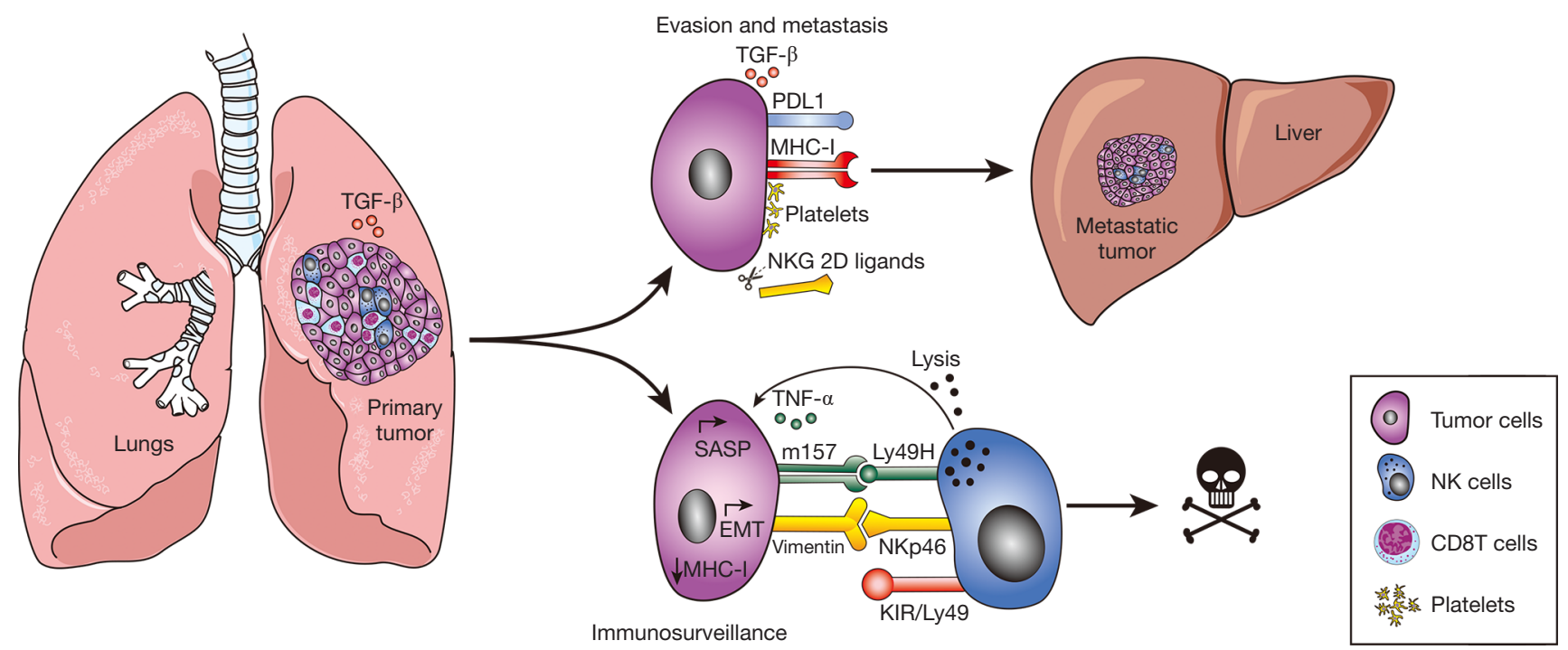

Figure 2 Tumor cell evasion and surveillance by NK cells. Primary tumor cells that metastasize harness mechanisms to actively evade immunosurveillance. This includes the secretion of TGF- $\beta$, expression of PD-L1 and MHC-I ligands, platelet association and the secretion of NKG2D ligands, inhibiting the NK cell cytotoxic response. Conversely, primary tumor cells that are effectively killed by NK cells express activating ligands to NK cell receptors through the upregulation of SASP and EMT gene regulation pathways (i.e., TNF- $\alpha$, vimentin, m157) or downregulate the inhibitory ligand MHC-I, initiating lysis of target cells. TGF- $\beta$, transforming growth factor beta; PD-L1, programmed cell death ligand 1; MHC-I, major histocompatibility complex 1; SASP, senescence associated secretory phenotype; TNF- $\alpha$, tumor necrosis factor alpha; EMT, epithelial to mesenchymal transition; KIR, killer immunoglobulin-like receptor.

NK cell deficiency $(30,31)$. This observation is further supported by a long-term study whereby increased NK cell activity negatively correlated with the likelihood of developing cancer (32). Recently, the association between NK cell infiltration of solid tumors has been found to be prognostic. By selectively combining immune gene signatures $(33,34)$, Cursons et al. distilled an NK signature to deconvolute NK cells, cytokines and ligands present in the tumor microenvironment (TME). When applying the NK signature to melanoma datasets, an increased NK score stratified patients with improved survival, suggesting that NK cell infiltration is prognostic in this setting (35). A similar approach has been adopted by others, whereby a signature based on NK cell and dendritic cell infiltration also stratified patient survival in melanoma, head and neck squamous cell carcinoma (HNSCC) and lung adenocarcinoma (LUAD) (36). In line with transcriptional studies, NK cell infiltration was quantified using CD57 immunostaining, which also revealed a positive correlation with prognosis in gastric $(37)$ and colorectal $(38,39)$ cancer patients. Together, these findings suggest that NK cells play a critical role in cancer immune surveillance and prognosis.
The tumor microenvironment can suppress NK cell activity through secreted factors to evade immunosurveillance (Figure 2). Transforming growth factor beta (TGF- $\beta$ ), a multifunctional cytokine, inhibits the activity of NK cells (40). The binding of TGF- $\beta$ to its cognate receptor on the NK cell surface (TGF- $\beta$-receptor II; TGF $\beta$ RII) provides signals that inhibit the mammalian target of rapamycin (mTOR) pathway. This results in reduced NK cell proliferation, survival and activity (41). In conditional knockout mice, whereby TGFBRII deletion is restricted to NKp46-expressing NK cells (NKp46-Cre) $\left.T G F \beta R I I^{\Delta / \Delta}\right)$, the inhibitory effect of TGF- $\beta$ on NK cells was ablated (42). It has also been found that members of the TGF- $\beta$ superfamily, such as Activin-a, similarly inhibit NK cell activity. Inhibition of Activin-a signaling through the use of Follistatin, an activin binding and neutralizing glycoprotein, reduced the metastatic burden in B16F10 melanoma cells in an intravenous (i.v.) transplantation mouse model (43). These findings highlight the importance of the TGF- $\beta$ pathway in NK cell activity. Indeed, NK cells are not only regulated by the TGF superfamily in the TME. Adenosine, an anti-inflammatory metabolite, 
has also been found to negatively influence NK cell proliferation and maturation through the engagement of the adenosine $\mathrm{A} 2 \mathrm{~A}$ receptor (A2AR) (44). In addition to inhibitory signaling pathways, there are also physiological barriers for NK cells in the TME of solid tumors $(45,46)$. In the microenvironment of colorectal liver metastasis, for example, NK cells have been found to undergo apoptosis due to the acidic conditions (47). Therefore, tumor cells reside in a TME which is inhospitable to NK cell survival and activity, constraining immunosurveillance. Counteracting the effect of the TME could be an alternative approach to re-engaging innate defense processes.

In addition to an inhibitory microenvironment, tumor cells directly evade NK cell surveillance through the altered regulation of ligands and their association with platelets (28). NKG2D is a key activating receptor on NK cells (48). Through the downregulation of NKG2D ligands, tumor cells can evade the cytotoxic NK cell response (Figure 2) (49,50). Specifically, cancers can shed NK cell activating stress ligands through proteolytic processes, removing the ligands from their cell surface (51). Importantly, antibody mediated inhibition of NKG2D ligand shedding resulted in enhanced NK cell activity, highlighting the possibility of countering this evasion mechanism (51). The importance of NKG2D ligand availability is exemplified in Cursons et al. where bioinformatic approaches demonstrated that NK cell infiltration was ineffective in the absence of activating ligands (35). Furthermore, platelets have long been associated with cancer metastasis, forming a protective 'barrier' on disseminating tumor cells. This mechanism effectively shields tumor cells from NK cell immunosurveillance as well as facilitating metastatic dissemination $(52,53)$. Co-incubation of platelets with tumor cells has identified that platelets can impair NK cell activity by a myriad of mechanisms, including the secretion of TGF- $\beta$ (54), transfer of functional MHC-I to the tumor cell surface (55) and initiating NKG2D ligand shedding by tumor cells (56). Platelets thereby hinder NK cell function both directly and indirectly to facilitate tumor cell evasion of NK cell cytotoxicity and surveillance.

\section{Systemic barriers to NK cell activity}

NK cells are not only impacted by the TME or the tumor cells themselves, but have also been shown to be effected by systemic environmental and therapeutic agents. Lung cancer has a strong association with cigarette smoke exposure, which has been demonstrated to directly impact NK cell function. Likewise, chemotherapy, a first line therapy for the majority of lung cancer patients, has also displayed an impact on NK cell activity.

Cigarette smoke exposure significantly alters the lung immune environment (57). Increased metastatic burden has been observed in smoke exposed mice i.v. injected with the melanoma cell line B16-M05 (58). This increased burden was directly attributed to poorly functional NK cells due to an inhibitory effect of smoke exposure (58). Cigarette smoke reduces the production of IL-15, thereby impairing NK cell cytolytic capabilities $(59,60)$. The influence of cigarette smoke has long-term impacts on NK cells, with reduced numbers of circulating NK cells present in the lungs of cigarette smokers years after cessation (61). Taken together, NK cells are sensitive to the effects of cigarette smoke in both reducing their functionality and numbers in lung tissue.

In the setting of cancer, it is important to be aware that chemotherapy can also impact NK cell activity. Administration of chemotherapy and other cancer treatment modalities, such as radiotherapy and cytostatic drugs, elevates the expression of stress signals on the surface of tumor cells, which increases their visibility to NK cells (62). However, in vitro studies investigating the effect of cancer therapeutics on NK cell activity have highlighted potential adverse effects. Microtubule inhibitors, such as Paclitaxel and Vinblastine, were found to reduce the ability of NK cells to lyse the leukemia K562 cell line in culture (63), suggesting that chemotherapy has deleterious effects on NK cell activity. This effect has also been observed in clinical studies in non-small cell lung cancer (NSCLC). Patients treated with Paclitaxel initially exhibited reduced NK cell activity upon receiving treatment. However, during the course of treatment NK cell activity was restored (64), suggesting the inhibitory effect of chemotherapy on NK cells may be transient. Whether chemotherapy negatively or positively influences NK cell activity also appears to be dependent on dosage, adding additional layers of complexity to this process (62). Therefore, when considering the cancer setting it is important to take into account the effect of the chemotherapeutic agent in increasing NK cell activating signals, which must outweigh the negative effect of chemotherapy on the NK cells themselves.

\section{Lung cancer}

Given the utility of NK cells in the control of tumor cell 
dissemination in solid tumors, it is likely that NK cells also play a key role in the control of lung cancer cells. Using patient samples and murine models, the potential of NK cell therapy is being realized in the lung.

\section{NK cell infiltration}

It has recently been identified that NK cell infiltration positively correlates with survival in many solid tumors $(35,36)$. While the degree of NK cell infiltration in the primary tumor does not necessarily dictate the potential efficacy of NK cell therapy, it does provide an indication of the current level of control NK cells exert on lung cancer. Patients with NK cell defects are prone to developing tumors (65), while NK cells in the peripheral blood of cancer patients have poorer cytotoxicity compared to healthy individuals (66). These studies highlight the systemic interaction between NK cells and tumor cells in the patient.

In lung cancer patients, NK cell infiltration has been assessed in specimens through immunostaining and flow cytometry of primary material. Although reports of NK cell infiltration and patient outcome are mixed for NSCLC; from no correlation (67-69), to prognostic (70-72); squamous cell carcinoma (LUSC) does seem to display increased infiltration compared to LUAD (69,72-74). NK cells infiltrating NSCLC appear to have reduced cytotoxic function $(68,75,76)$, likely due to a tumor microenvironment rich in TGF- $\beta$ (42). Encouragingly, while tumor-infiltrating NK cells exhibit reduced cytotoxic function, no difference in cytokine production between NK cells infiltrating the tumor or adjacent lung tissue has been identified (76). This suggests that NK cells play an important role in the immune microenvironment of NSCLC.

Recently, infiltration of NK cells into SCLC has been quantified by flow cytometry. The study compared the proportion of $\mathrm{CD}^{+} \mathrm{T}$ cells and $\mathrm{NK}$ cells in endobronchial ultrasound-guided transbronchial needle aspirate (EBUSTBNA) SCLC tumor material and matched peripheral blood mononuclear cells (PBMCs) from a cohort of SCLC patients (77). Strikingly, while the proportion of $\mathrm{CD} 8^{+}$ $\mathrm{T}$ cells remained unchanged between PBMC and SCLC samples, NK cells were consistently reduced in SCLC, suggesting active reduction of this cytotoxic immune cell type. The analysis further applied the NK infiltration signature (35) to the recently stratified SCLC subtypes, ASCL1, NEUROD1, YAP1 and POU2F3 (78). The POU2F3 subtype displayed a consistently increased immune signature, while the ASCL1 subtype had a broad spectrum, irrespective of patient stage (77). This suggests the presence of heterogeneity in immune infiltration between the SCLC subtypes, similar to that observed in the NSCLC subtypes.

\section{Non-small cell lung cancer}

Beyond studying the lung as a secondary site of metastasis, investigation of lung cancer cells themselves and their ability to evade or be targeted by NK cells is essential in evaluating their therapeutic potential. In lung cancer, the most exhaustive investigation of NK cell activity has been explored in LUAD, the most prevalent subtype of NSCLC. This is largely due to the availability of syngeneic murine models with an intact immune environment (Table 1).

Similar to patient samples $(73,75)$, quantification of NK cells infiltrating murine models of LUAD reveal a decreased frequency as the primary tumor develops in the lung $(83,84)$. However, the key role NK cells play in early tumor development (29) and the control of metastatic dissemination (82) are becoming apparent (Figure 2).

Epithelial to mesenchymal transition (EMT) is a process that promotes solid tumor dissemination and has been found to be associated with a high NK cell signature score in melanoma (35). In the A549 human LUAD cell line, TGF- $\beta$-induced EMT (86) was found to modulate the expression of NK-activating ligands, leading to increased susceptibility of NK cell killing (82). Indeed, EMTinduced A549 cells metastasize in vivo when injected into the flanks of NK deficient CB17SC-beige mice (79). Strikingly, in $\mathrm{Rag}^{-/-}$mice, depletion of NK cells using the anti-ASGM1 antibody resulted in increased spontaneous lung metastasis of EMT-induced A549 cells; with no impact on primary tumor growth (82). Furthermore, the murine Lewis Lung Cancer (LLC) cell line transplanted into immune competent $\mathrm{C} 57 \mathrm{Bl} / 6$ mice metastasized only when NK cells were depleted (82). This evidence suggests that NK cells are key cytotoxic effectors in the control of metastatic dissemination in LUAD models. A critical factor in metastatic dissemination is the process of EMT, providing a double-edged sword to NK cells. TGF- $\beta$ in the primary tumor microenvironment inhibits NK cell activity (42) and induces EMT in LUAD cells enabling metastatic dissemination, thus modulating NK ligand expression making the tumor cells more vulnerable to NK immunosurveillance.

Consistent with the effects of TGF- $\beta$ on NK cells (42), the microenvironment of LUAD has been shown to be 


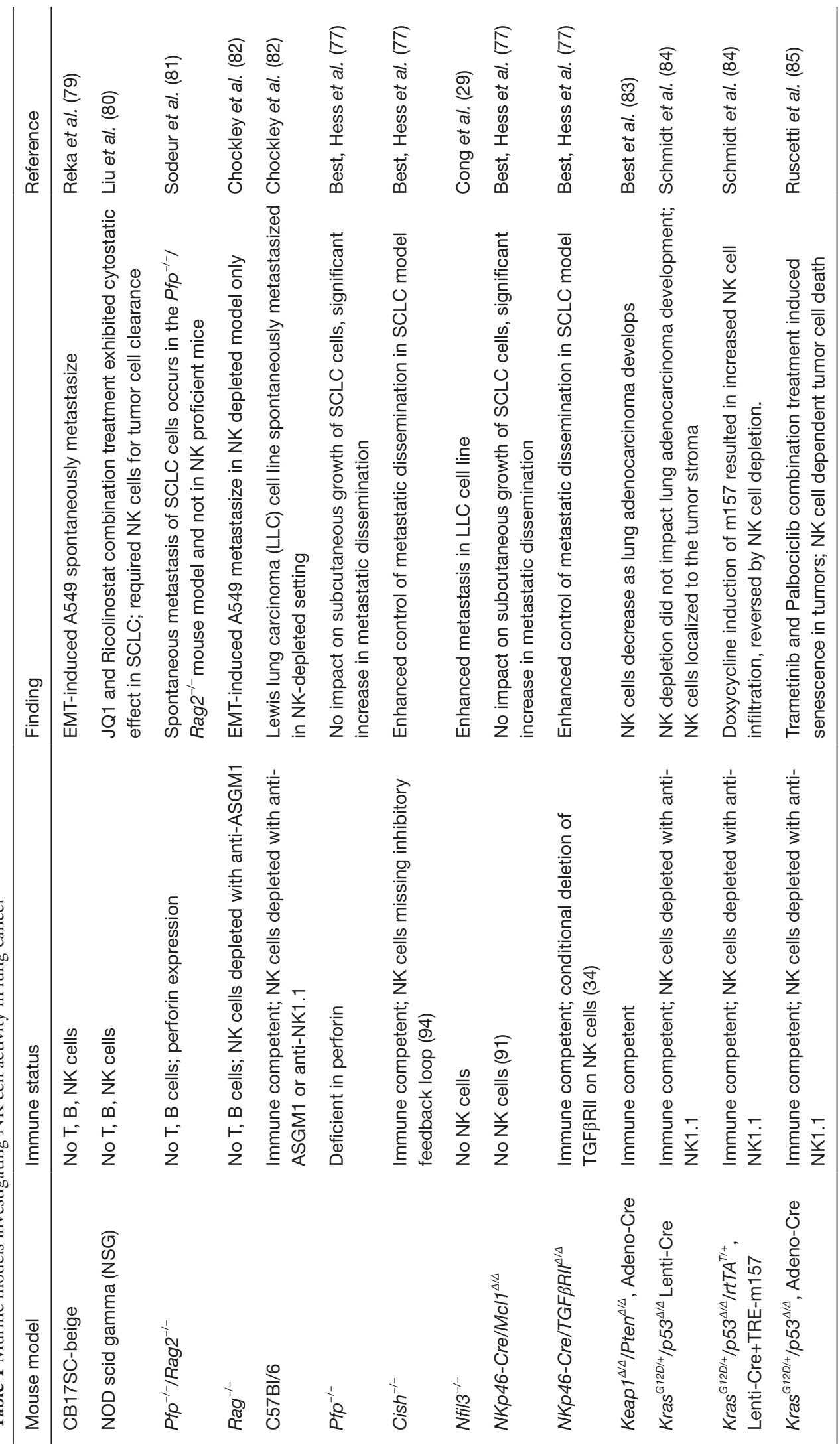


detrimental to NK cell function in murine models. To critically study the TME, tumors must develop from lung epithelia in immune-competent murine models. To this end, the $\mathrm{Kras}^{\mathrm{G} 12 \mathrm{D} /+}$ model of LUAD (87) has been utilized with or without the acceleration afforded by loss of $p 53(88,89)$ to investigate the effect of TME on NK function $(29,84)$. Administration of lentivirus encoding Cre recombinase directly into the lung results in spontaneous tumor development in $\mathrm{Kras}^{\mathrm{G} 12 \mathrm{D} /+}(\mathrm{K})$ and $\mathrm{Kras}^{\mathrm{G} 12 \mathrm{D} /+} /$ $p 53^{\mathrm{A} / \mathrm{fl}}(\mathrm{KP})$ mice, where NK cell activity can be analyzed. In lungs bearing KP tumors, NK cells were identified in the tumor stroma and displayed a reduced capacity to produce cytokines when stimulated ex vivo $(29,84)$. Analysis of the TME in the tumors of $\mathrm{K}$ mice resulted in the identification a TGF- $\beta$-specific decrease of key NK cell effector proteins and glycolytic function (29). Furthermore, depletion of NK cells using anti-NK1.1 did not impact KP tumor progression (84), suggesting the reduced function and stromal location of NK cells renders them non-functional in the LUAD microenvironment. Moreover, a transcriptional program regulated by SOX2, a key transcription factor identified in KP metastases, results in the downregulation of MHC-I ligands. Critically, this results in selective 'pruning' of $\mathrm{SOX}^{+}$metastatic cells by NK cell killing, naturally reducing the heterogeneity of metastases in this model (57). In addition, forced expression of the NK cell-activating ligand m157 (activating the NK receptor Ly49H) on established KP lesions, resulted in enhanced infiltration and activation of NK cells, further boosted by the stimulating cytokine IL-15 (84). These findings suggest that the combination of enhanced NK ligand expression together with stimulation of NK activating pathways are capable of invigorating the NK cell response to target LUAD.

An alternative approach of harnessing NK cells to kill LUAD has been to repurpose the enhanced killing ability of NK cells to senescent cells. Using KRAS-mutant LUAD models, Ruscetti et al. investigated the potential of NK cell cytotoxicity to senescent cells (85). NK cells are attracted to senescence associated secretory phenotype (SASP) chemokines involved in recruitment (CCL2, CCL4, CCL5, CXCL10, CX3CL1) and cytokines to induce proliferation (IL-15, IL-18, TNF- $\alpha$ ) (90-92) released by senescent cells (93). KRAS-mutant LUAD cells induced to senescence through the combined inhibition of the MAPK (Trametinib) and CDK4/6 (Palbociclib) pathways induced enhanced cytotoxicity of NK cells (85). Strikingly, in the autochthonous KP model, the combination of Trametinib and Palbociclib induced tumor shrinkage in an NK cell dependent manner (85). SASP induced by oncogenic KRAS has been well documented (93) and now provides a compelling strategy to enhance NK mediated cytotoxicity independent of immune-activating agents (84). Furthermore, this study identifies one context in which NK cells can effectively target the primary tumor, suggesting that the SASP transcriptional program could be key to enticing NK cells to the primary lesion. It is plausible that the microenvironment of senescent cells switches from TGF- $\beta$ enriched to TNF- $\alpha$ dominant, a key cytokine in the SASP phenotype and integral to the NK cell response (85).

Overall, studies using LUAD models prove that substantial NK cell cytotoxicity can be leveraged to target both the primary and metastatic sites. Though NK cells poorly infiltrate $\operatorname{LUAD}(75,83,84)$, the activity of NK cells have great therapeutic potential $(29,82,84,85)$. This provides support for the potential of NK cells in targeting LUSC, where there is greater evidence of NK cell infiltration in patient samples $(72,74)$ and is more predictive of patient outcome (70,71). Therefore, NSCLC provides a promising avenue for the exploration of NK immunotherapy.

\section{Small cell lung cancer}

There is promising pre-clinical evidence to suggest that NK cell therapy may be highly suited in the treatment of SCLC. Key to the induction of NK cell cytotoxicity, MHC-I expression is reduced in SCLC primary biopsies and cell lines compared to other cancers, including NSCLC (94). This observation, potentially explaining poor T cell immunotherapy responses in SCLC (95), suggests that NK cell-based cytotoxicity may be crucial to SCLC control. Critically, primary tumor cell lines derived from the murine SCLC model, $p 53^{\Delta / \Delta} / R b 1^{\Delta / \Delta}$ (96), similarly displayed reduced MHC-I expression (97). This cell line model was further used to identify that epigenetic regulation controls MHC-I expression, which was reversible following inhibition of Ezh2, a member of the polycomb repressive complex (PRC2), sensitizing SCLC tumors to T cell mediated killing (97). This elegantly highlights the vulnerability of tumor cells to the cytotoxic arms of the immune system and that evasion of the MHCI-mediated $\mathrm{CD}^{+} \mathrm{T}$ cell response results in susceptibility to NK cell cytotoxicity.

Given that SCLC is a highly metastatic disease, it is tantalizing to hypothesize that NK cells play an important role in SCLC progression. Indeed, metastatic dissemination of SCLC has been identified as an immune- 
regulated process through the use of immune-deficient murine models (81). Subcutaneous transplantation of human SCLC cell lines (OH1, OH3, H69, H82) rarely results in spontaneous metastasis in murine models deficient in $\mathrm{B}$ and $\mathrm{T}$ cells. However, in the $P f p^{-/-} / \operatorname{Rag}_{2} \mathrm{I}^{-/-}$ immune-compromised mouse model, deficient of $\mathrm{B}$ and $\mathrm{T}$ cells with additional loss of perforin (Table 1), SCLC spontaneously metastasized in this NKimpaired model (81). The role of NK cells in metastatic immunosurveillance of SCLC has recently been corroborated in genetically engineered mouse models (77). Using an immune-competent metastatic SCLC model, cell lines generated from a primary $p 53^{\Delta / \Delta} / R b 1^{\Delta / \Delta}$ SCLC tumor were injected i.v. into syngeneic immune-competent recipients, resulting in liver metastasis. Genetic depletion of NK cells using the NKp46-Cre/Mcl1 ${ }^{\Delta / \Delta}$ model $(98,99)$, resulted in a significant increase of SCLC metastasis, while $\mathrm{T}$ cell depletion had no effect (77). Furthermore, genetically enhanced NK cells; Cish $^{-1-}(100)$ and NKp46Cre/TGFBRII $I^{\Delta / \Delta}$ (42) with no "brakes" on NK cell activation, or NK cells activated with cytokines (super IL2) were superior in regulating metastatic dissemination of SCLC cell lines (77). Together, these findings indicate that the baseline regulatory capacity of NK cells can be enhanced therapeutically to control metastatic dissemination of SCLC.

The contribution of NK cells to therapeutic outcomes is not limited directly to their activation. NK cells have been found to be vital to tumor cell clearance when drug combinations have cytostatic effects (80). The combination of cell cycle inhibitor (Ricolinostat ACY-1215) and epigenetic regulator (JQ1) were investigated in PDX from chemo-refractory SCLC patients and human SCLC cell lines (80). Strikingly, the anti-tumor effect of combination treatment that was present in $\mathrm{T}$ cell deficient nude mice was abolished in immune-deficient recipient NOD scid gamma (NSG) mice (Table 1). The key difference between these immune-deficient mouse models is the presence of NK cells in nude mice, which were found to mediate cytotoxicity due to increased MHC-II expression on tumor cells following combination therapy (80). This finding highlights the importance of NK cells in improving the outcome of conventional therapeutic strategies. Taken together, these findings highlight the significance of $\mathrm{NK}$ cell regulation in SCLC, due to reduced MHC-I expression and enhanced metastatic dissemination. NK cell immunotherapy is therefore a promising therapeutic modality for SCLC patients that requires further investigation in a clinical setting.

\section{NK cell therapy}

Mounting evidence for the beneficial role of NK cells in the detection and control of cancer and a greater understanding of NK cell biology have driven a renaissance in drug discovery for NK cell immunotherapy (Table 2). NK cell immunotherapy can be approached from two directions: the activation of endogenous NK cells currently circulating or resident within tissues or tumors; or the administration of activated autologous or allogeneic NK cells.

\section{Activation of NK cells}

The stimulation of endogenous NK cells can be achieved through administration of cytokines or cell signaling peptides that potentiate cytotoxic immune cell function and homeostasis. Cytokines that activate the immune system, such as interleukin-2 (IL-2) and IL-15 activate signaling cascades that enhance the activity of NK cells (100). Clinically, activation of the immune system using cytokine therapy has been used primarily in melanoma and renal cell carcinoma, where IL-2 and IFN- $\alpha$ have been the primary therapeutic modality until recent advances in clinical practice (109). The therapeutic use of cytokines, however, promotes a systemic response and can, in certain cases, reduce immune cell activity. Indeed, in stem cell transplants with adjuvant ultra-low dose of IL-2 cytokine therapy, regulatory $\mathrm{T}$ cell activity was enhanced (110). However, the systemic nature of cytokine therapy carries the risk of side effects, such as fever, resulting from overactivation of the immune system (111). To mitigate these risks, considerable effort has been applied to improve cytokine therapy $(112,113)$. For example, recombinant IL-2R $\alpha$ linked to an NKG2D binding protein (OMCP-mutIL-2) (114). This modified cytokine activates IL-2 signaling only in NKG2Dexpressing cells, NK cells, alleviating the majority of offtarget effects from systemic cytokine use (114).

The principal cytokine for NK cell development and homeostasis, IL-15, is also receiving therapeutic interest $(109,115)$. To improve the biological activity of IL-15, it is complexed with its' receptor, IL-15R $\alpha$, which significantly enhances its availability (116). This IL-15/IL-15R $\alpha$ complex displays enhanced efficacy compared to IL-15 alone and rapidly induces NK cell activation (116). In a first-inhuman trial, administration of the IL-15/IL-15R complex as recombinant human IL-15 (rhIL-15), resulted in a robust 


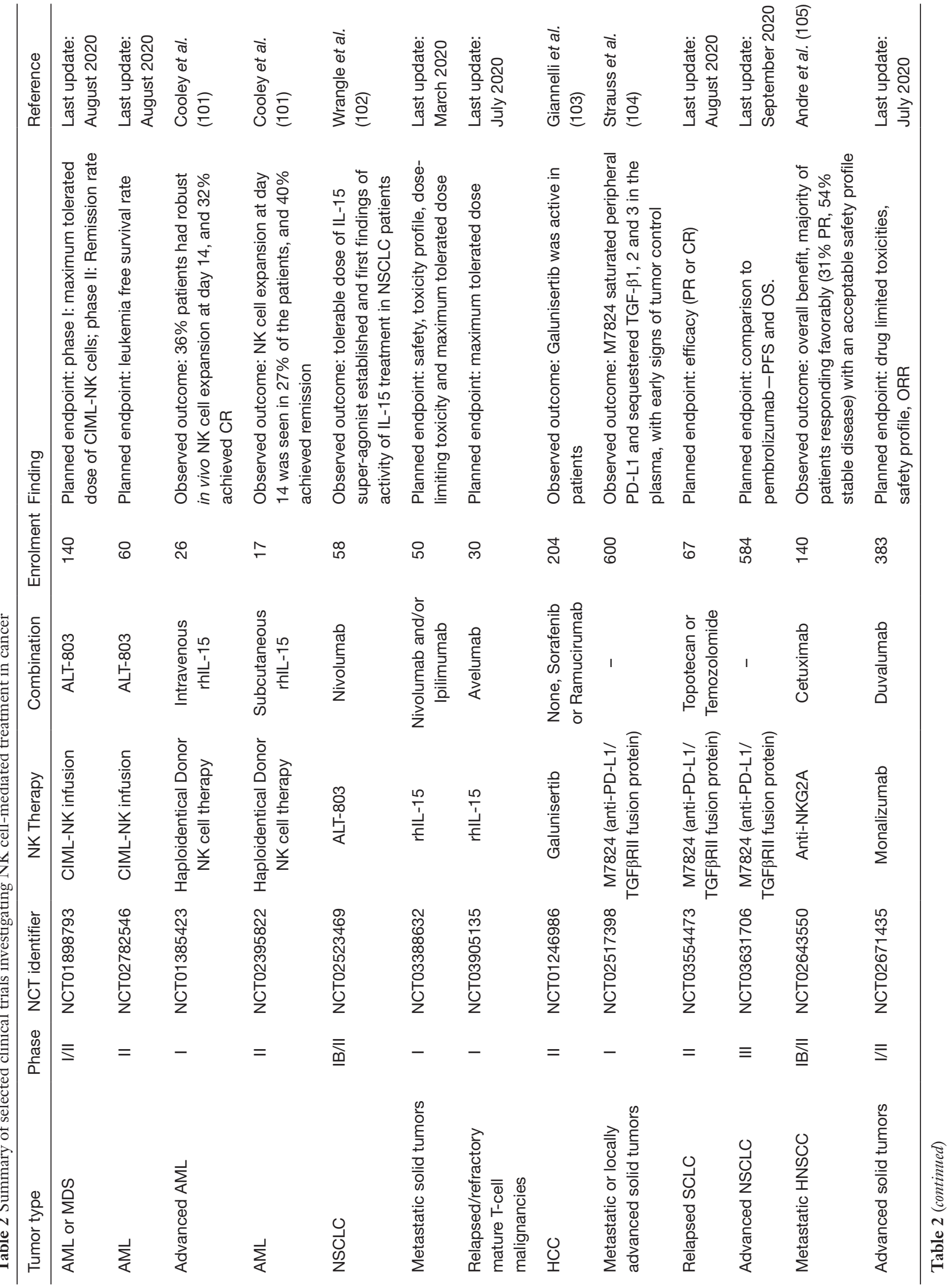




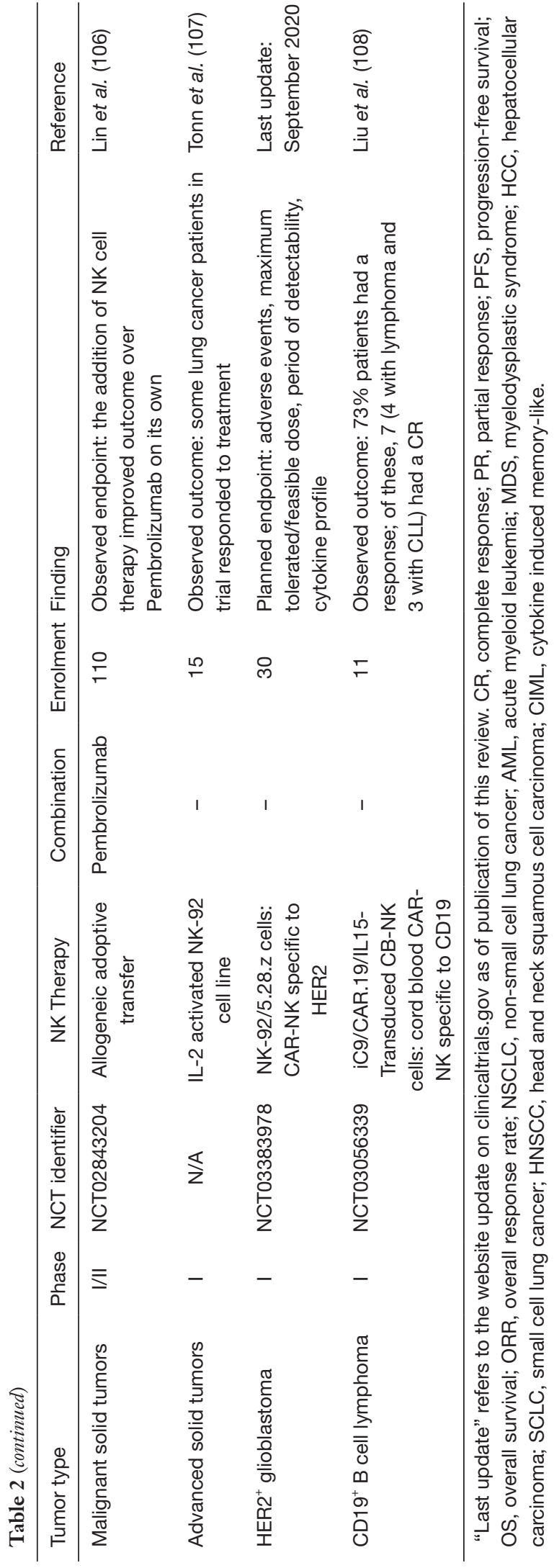

expansion of circulating NK cells in acute myeloid leukemia (AML) patients (NCT02395822, NCT01385423) (101). Patients additionally exhibited cytokine release syndrome, which required additional immune-modulatory treatment. Though no objective response was observed, the trial has established a clinical potential of rhIL-15 in enhancing NK cell activity (101). Currently, rhIL-15 is being investigated in combination with $\mathrm{T}$ cell immunotherapy to further explore its therapeutic use (Nivolumab and/or Ipilimumab in metastatic solid tumors: NCT03388632; Avelumab in T-cell malignancies: NCT03905135). An alternative IL15 complex, ALT-803 (IL-15/IL-15R $\alpha / \mathrm{IgG} 1 \mathrm{Fc} / \mathrm{N} 72 \mathrm{D}$ ) is a super-agonist of IL-15 and substantially increases the levels of circulating $\mathrm{CD} 56^{\text {bright }} \mathrm{NK}$ cells (117). In a Phase Ib clinical trial, ALT-803 combined with Nivolumab (NCT02523469) was well-tolerated in metastatic NSCLC patients with increased numbers and activity of NK cells (102). Promisingly, of 11 subjects who relapsed with Nivolumab alone, 3 subjects exhibited a partial response to the combination with ALT-803, suggesting that the IL15 super-agonist may be efficacious in NSCLC (102). Furthermore, the combination of subcutaneous ALT-803 injection with adoptive transfer of NK cells (NCT01898793, NCT02782546) enhances NK cell activity without severe adverse events (118), highlighting the potential utility of this treatment modality. Taken together, IL-15-based cytokine therapy holds promise in the adjuvant treatment of lung cancer.

A key mediator of NK cell activity is TGF- $\beta$, whose therapeutic inhibition has the potential to enhance the activity of NK cells. Currently, clinical trials are assessing the efficacy of TGF- $\beta$ pathway inhibition using small molecules (galunisertib) in hepatocellular carcinoma (NCT01246986) (103), or biologics (M7824) in metastatic or locally advanced solid tumors (NCT02517398) (104), relapsed SCLC (NCT03554473) and advanced NSCLC (NCT03631706). The small molecule galunisertib (LY2157299) is an inhibitor of the TGF- $\beta$ receptor (TGF- $\beta 1$ receptor type I) and results in downregulation of SMAD2 phosphorylation, consistent with inhibition of the TGF- $\beta$ pathway $(119,120)$. In a Phase II clinical trial, galunisertib treatment is manageable and active in hepatocellular carcinoma patients $(103,121)$. The biologic molecule M7824 is a bifunctional anti-PD-L1/TGFßRII fusion protein, with enhanced anti-tumor response compared to targeting each molecule in isolation $(122,123)$. Strikingly, in Phase I clinical trials, M7824 saturated peripheral PD-L1 and sequestered TGF- $\beta 1,2$ and 3 in the plasma, with early 
signs of tumor control (104). Although the M7824 trial in relapsed SCLC (NCT03554473) and advanced NSCLC (NCT03631706) are yet to report findings, the efficacy of TGF- $\beta$ signaling pathway inhibition is promising. It is likely that the systemic inhibition of TGF- $\beta$ signaling enhances NK cell activity, however this has not yet been described in the current trials.

The systemic activation of NK cells can also be achieved through checkpoint inhibition of $\mathrm{NKG} 2 \mathrm{~A}$, the cognate receptor for $\mathrm{MHC}-\mathrm{I}$ recognition. As described above, the presence of MHC-I results in an inhibitory signal in NK cells, ligating with the NKG2A/CD94 complex on the NK cell surface. Recently, a monoclonal humanized antiNKG2A IgG4-blocking antibody, Monalizumab, has been developed to block the interaction between MHC-I and NKG2A, thus ablating this significant inhibitory pathway in NK cells (105). Significantly, in murine pre-clinical studies anti-NKG2A was found to synergize with anti-PD-L1 $\mathrm{T}$ cell immunotherapy and vastly improve survival (105). Though NKG2A is additionally expressed on $\mathrm{CD}^{+} \mathrm{T}$ cells and anti-NKG2A enhances $\mathrm{CD}^{+} \mathrm{T}$ cell activity, tumor control was dependent on the presence of NK cells as highlighted by the loss of tumor control in combination with the NK depletion antibody, anti-asailo-GM1 (105). This finding further highlights the phenomenon of antibody-dependent cellular cytotoxicity (ADCC), where NK cells contribute to the efficacy of $\mathrm{T}$ cell immunotherapy $(10,124,125)$. Inhibition of NKG2A has been assessed in the clinic in combination with cetuximab in HNSCC patients (NCT02643550). Promisingly, in significantly pre-treated patients (platinum-based chemotherapy, T cell immunotherapy, cetuximab alone) this strategy provided overall benefit, with the majority of patients responding favorably (31\% partial response, 54\% stable disease) with an acceptable safety profile (105). Ongoing trials of Monalizumab in combination with Duvalumab (metastatic colorectal cancer: NCT02671435) (126) and cetuximab (colorectal cancer: NCT02671435) additionally support the use of NK cell checkpoint blockade immunotherapy in solid tumors. It is tantalizing to speculate that NK cell immunotherapy in lung cancer is now within reach.

\section{Adoptive transfer of NK cells}

An alternative approach to the systemic activation of NK cells is to directly introduce activated NK cells to a patient, known as adoptive transfer. Generation of NK cells suitable for adoptive transfer can be procured from multiple sources, including peripheral blood from healthy adults, stem cells from cord blood, induced pluripotent stem cells and NK cell lines. Isolated NK cells are activated by exposure to stimulatory signals such as cytokines (127) or permanently augmented by genetic manipulation (22).

Adoptive transfer of a patients' own NK cells (autologous transfer) enables ex vivo stimulation and expansion prior to re-administration as a therapeutic modality. Clinical trials employing autologous NK cell transfer have been performed in hematopoietic and solid tumors. In a clinical study of metastatic melanoma and renal cell carcinoma, adoptive transfer of in vitro activated autologous NK cells identified persistent activated NK cells in the circulation (128). Although the transferred NK cells displayed high cytolytic potential when expanded in vitro, the transferred NK cells required further in vivo activation with IL-2, suggesting that autologous transfer should be used in combination with systemic cytokine therapy (128). A study in advanced NSCLC patients treated with ex-vivo expanded autologous NK cell therapy in combination with docetaxel was similarly performed to evaluate feasibility of autologous transfer (129). No therapeutic benefit was obtained from the combination, likely due to poor NK cell activity in vivo, however this was not assessed in the study (129). Though autologous NK cells can be expanded and activated in vitro, the limited clinical success suggests that this approach is not a feasible treatment modality. This is possibly due to the recognition of the self-MHC-I (130), or the requirement for additional in vivo stimulation (128). Taken together, these findings suggest that autologous transfer of NK cells is not an optimal therapeutic approach in the clinic.

Adoptive transfer of 'foreign' NK cells (alloreactive transfer) results in MHC-I mismatch and an efficient immune response. Alloreactive transfer of KIR ligand incompatible donor NK cells were found to efficiently target AML cells and provided a prolonged protective response (131). Following this initial discovery, clinical trials exploring the adoptive transfer of mismatched alloreactive NK cells as a form of immunotherapy have minimal toxicity and exhibited preliminary success in hematopoietic malignancies and solid tumors including NSCLC $(132,133)$. Strikingly, in late-stage NSCLC, repetitive infusions of alloreactive donor NK cells resulted in partial response or disease stabilization in the majority of patients (111), highlighting the potential efficacy and safety in the lung cancer setting. Furthermore, a clinical study in advanced NSCLC patients investigated the effect of allogeneic NK cell transfer combined with pembrolizumab 
(NCT02843204) (106). This study identified enhanced NK cell activity in patients receiving NK cells, together with improved survival compared to patients receiving pembrolizumab alone (106). Together, these findings provide preliminary clinical evidence that alloreactive mismatched NK cell transfer can provide clinical benefit in lung cancer, laying the foundation for more extensive clinical investigation.

To expand the therapeutic use of alloreactive NK cells, human NK cell lines have been generated as a renewable source of NK cells. The human NK cell line NK-92, originally derived from a lymphoma patient (134), is highly cytotoxic against a variety of cancer types $(135,136)$ and has received Food and Drug Administration (FDA) approval for use in clinical trials (137). The NK-92 cell line has been used as a source of NK cells for adoptive transfer and modified for improved efficacy and target specificity. Examples of modification include genetic manipulation and cytokine activation prior to adoptive transfer. In a Phase I trial interrogating advanced solid tumors, infusion of NK-92 cells performed particularly well in the lung cancer patient cohort (107). Three of four lung cancer patients (SCLC and NSCLC) in the study displayed mixed response or prolonged stable disease in response to the adoptive transfer of IL-2 activated NK-92 cells (107). It is hypothesized that NK cells reside in the lung, prior to circulating following intravenous administration (138), which could explain the favorable response in lung cancer patients in the Phase I trial (107). While there are numerous benefits of utilizing cultured NK cells, there are however also limitations to their use. To ensure the cells do not divide uncontrollably within the patient, NK cell lines are irradiated prior to adoptive transfer and therefore have a limited lifespan and efficacy period. However, these early clinical trials suggest that the beneficial effects of NK cell autologous transfer can last well beyond their initial infusion.

To enhance the benefits of NK-92 infusion, genetic manipulation can be additionally performed to enhance NK cell activity and target specificity. A genetic method that has recently gained traction is the introduction of chimeric antigen receptors (CAR) on the surface of NK cells that act as targeting ligands to increase affinity to specific antigens (22). This technology used has been developed and optimized in T cells (CAR-T cells) and has been successfully applied to NK cells (9). Modification of the NK-92 cell line with CAR specific to the antigen HER2 are currently being trialed in HER2 ${ }^{+}$Glioblastoma patients (NCT03383978). Additionally, CAR-NK cells targeting the CD19 antigen
(anti-CD19 CAR-NK), prominent in B cell lymphoma, have been engineered from HLA-mismatched NK cells derived from cord blood (108). In a Phase I and II trial of 11 patients with $\mathrm{CD} 19^{+} \mathrm{B}$ cell malignancies, the majority of patients had complete remission following anti-CD19 CAR-NK therapy (108). Significantly, patients undergoing CAR-NK cell immunotherapy did not experience significant adverse events that have been observed following CAR-T therapy (139), and the anti-CD19 CAR-NK cells persisted for at least 12 months (108). These studies lay the foundations for successful implementation of CARNK therapy, and likely with the success of CAR-T cells, we envisage broad implementation of CAR-NK therapy in the cancer setting.

The application of NK therapy as a standalone agent or in combination with other therapeutic modalities is a rapidly evolving field that is producing promising results. Pre-clinically, NK cells have been shown to play a crucial role in metastatic tumor surveillance in both NSCLC and SCLC. Although these findings have yet to fully be realized in a clinical setting, they highlight a potential therapeutic modality in a field with limited treatment options and a low survival rate. Indeed, the application of NK cell immunotherapy has significantly progressed in recent years, with the most recent clinical trials showing tremendous potential. Although the clinical focus of NK cell therapy is largely in hematopoietic malignancies, the research outlined in this review highlights the conceivable progression of NK cell immunotherapy in the treatment of lung cancer.

\section{Acknowledgments}

We thank W. Hertan and P. Maltezos for assistance with figure production and N.D. Huntington (Monash University, Australia) for critical reading and feedback. JBH is supported by a University of Melbourne Research Scholarship and KDS is supported by the Peter and Julie Alston Centenary Fellowship.

Funding: This work was supported by the Australian National Health and Medical Research Council, Australia (Project Grant 1159955 to KDS) and was made possible through Victorian State Government Operational Infrastructure Support and Australian Government NHMRC IRIISS.

\section{Footnote}

Provenance and Peer Review: This article was commissioned 
by the Guest Editor (Daniel Steinfort) for the series "Lung cancer and the immune system" published in Translational Lung Cancer Research. The article has undergone external peer review.

Peer Review File: Available at http://dx.doi.org/10.21037/ tlcr-20-765

Conflicts of Interest: All authors have completed the ICMJE uniform disclosure form (available at http://dx.doi. org/10.21037/tlcr-20-765). The series "Lung cancer and the immune system" was commissioned by the editorial office without any funding or sponsorship. KDS reports grants from National Health and Medical Research Council (NHMRC), other from Peter and Julie Alston WEHI Centenary Fellowship, during the conduct of the study; personal fees from Honoraria AGIOS Pharmaceuticals and Cygnal Therapeutics, outside the submitted work. The authors have no other conflicts of interest to declare.

Ethical Statement: The authors are accountable for all aspects of the work in ensuring that questions related to the accuracy or integrity of any part of the work are appropriately investigated and resolved.

Open Access Statement: This is an Open Access article distributed in accordance with the Creative Commons Attribution-NonCommercial-NoDerivs 4.0 International License (CC BY-NC-ND 4.0), which permits the noncommercial replication and distribution of the article with the strict proviso that no changes or edits are made and the original work is properly cited (including links to both the formal publication through the relevant DOI and the license). See: https://creativecommons.org/licenses/by-nc-nd/4.0/.

\section{References}

1. Trinchieri G. Biology of natural killer cells. Advances in immunology. Elsevier, 1989:187-376.

2. Abel AM, Yang C, Thakar MS, et al. Natural killer cells: development, maturation, and clinical utilization. Front Immunol 2018;9:1869.

3. Sedlmayr P, Schallhammer L, Hammer A, et al. Differential phenotypic properties of human peripheral blood CD56dim+ and CD56bright+ natural killer cell subpopulations. Int Arch Allergy Immunol 1996;110:308-13.

4. Frey M, Packianathan NB, Fehniger TA, et al. Differential expression and function of L-selectin on CD56bright and CD56dim natural killer cell subsets. J Immunol 1998;161:400-8.

5. Bald T, Krummel MF, Smyth MJ, et al. The NK cellcancer cycle: advances and new challenges in NK cellbased immunotherapies. Nat Immunol 2020;21:835-47.

6. Trambas CM, Griffiths GM. Delivering the kiss of death. Nat Immunol 2003;4:399-403.

7. Sutlu T, Alici E. Natural killer cell-based immunotherapy in cancer: current insights and future prospects. J Allergy Clin Immunol 2009;266:154-81.

8. Zamai L, Ahmad M, Bennett IM, et al. Natural killer (NK) cell-mediated cytotoxicity: differential use of TRAIL and Fas ligand by immature and mature primary human NK cells. J Exp Med 1998;188:2375-80.

9. Shimasaki N, Jain A, Campana D. NK cells for cancer immunotherapy. Nat Rev Drug Discov 2020;19:200-18.

10. Barry KC, Hsu J, Broz ML, et al. A natural killer-dendritic cell axis defines checkpoint therapy-responsive tumor microenvironments. Nat Med 2018;24:1178-91.

11. Mocikat R, Braumüller H, Gumy A, et al. Natural killer cells activated by $\mathrm{MHC}$ class Ilow targets prime dendritic cells to induce protective CD8 T cell responses. Immunity 2003;19:561-9.

12. Hayakawa Y, Huntington ND, Nutt SL, et al. Functional subsets of mouse natural killer cells. Immunol Rev 2006;214:47-55.

13. Orange JS. Human natural killer cell deficiencies and susceptibility to infection. Microbes Infect 2002;4:1545-58.

14. Orange JS, Hossny EM, Weiler CR, et al. Use of intravenous immunoglobulin in human disease: a review of evidence by members of the Primary Immunodeficiency Committee of the American Academy of Allergy, Asthma and Immunology. J Allergy Clin Immunol 2006;117:S525-53.

15. Marquardt N, Kekäläinen E, Chen P, et al. Human lung natural killer cells are predominantly comprised of highly differentiated hypofunctional CD69- CD56dim cells. J Allergy Clin Immunol 2017;139:1321-30.

16. Ferlazzo G, Carrega P. Natural killer cell distribution and trafficking in human tissues. Front Immunol 2012;3:347.

17. Carson WE, Giri JG, Lindemann $M$, et al. Interleukin (IL) 15 is a novel cytokine that activates human natural killer cells via components of the IL-2 receptor. J Exp Med 1994;180:1395-403.

18. Björkström NK, Ljunggren H-G, Michaelsson J. Emerging insights into natural killer cells in human 
peripheral tissues. Nat Rev Immunol 2016;16:310-20.

19. Marquardt N, Sharenberg M, Mold JE, et al. High-dimensional analysis reveals a distinct population of adaptive-like tissue-resident $\mathrm{NK}$ cells in human lung. bioRxiv 2019. doi: https://doi. org/10.1101/2019.12.20.883785

20. Vivier E, Tomasello E, Baratin M, et al. Functions of natural killer cells. Nat Immunol 2008;9:503-10.

21. Marquardt N, Kekäläinen E, Chen P, et al. Unique transcriptional and protein-expression signature in human lung tissue-resident NK cells. Nat Commun 2019;10:3841.

22. Souza-Fonseca-Guimaraes F, Cursons J, Huntington ND. The emergence of natural killer cells as a major target in cancer immunotherapy. Trends Immunol 2019;40:142-58.

23. Chan CJ, Smyth MJ, Martinet L. Molecular mechanisms of natural killer cell activation in response to cellular stress. Cell Death Differ 2014;21:5-14.

24. Lanier LL. NK cell recognition. Annu Rev Immunol 2005;23:225-74.

25. Freeman AJ, Vervoort SJ, Ramsbottom KM, et al. Natural killer cells suppress $\mathrm{T}$ cell-associated tumor immune evasion. Cell Rep 2019;28:2784-94.

26. Long EO, Sik Kim H, Liu D, et al. Controlling natural killer cell responses: integration of signals for activation and inhibition. Annu Rev Immunol 2013;31:227-58.

27. Barrow AD, Martin CJ, Colonna M. The natural cytotoxicity receptors in health and disease. Front Immunol 2019;10:909.

28. Raulet DH, Gasser S, Gowen BG, et al. Regulation of ligands for the NKG2D activating receptor. Annu Rev Immunol 2013;31:413-41.

29. Cong J, Wang X, Zheng X, et al. Dysfunction of natural killer cells by FBP1-induced inhibition of glycolysis during lung cancer progression. Cell Metab 2018;28:243-55.

30. Lorenzi L, Tabellini G, Vermi W, et al. Occurrence of nodular lymphocyte-predominant hodgkin lymphoma in hermansky-pudlak type 2 syndrome is associated to natural killer and natural killer T cell defects. PLoS One 2013;8:e80131.

31. Orange JS. Natural killer cell deficiency. J Allergy Clin Immunol 2013;132:515-25.

32. Imai K, Matsuyama S, Miyake S, et al. Natural cytotoxic activity of peripheral-blood lymphocytes and cancer incidence: an 11-year follow-up study of a general population. Lancet 2000;356:1795-9.

33. Newman AM, Liu CL, Green MR, et al. Robust enumeration of cell subsets from tissue expression profiles. Nat Methods 2015;12:453-7.
34. Tosolini M, Pont F, Poupot M, et al. Assessment of tumorinfiltrating TCRV $\gamma 9 \mathrm{~V} \delta 2 \gamma \delta$ lymphocyte abundance by deconvolution of human cancers microarrays. Oncoimmunology 2017;6:e1284723.

35. Cursons J, Souza-Fonseca-Guimaraes F, Foroutan M, et al. A gene signature predicting natural killer cell infiltration and improved survival in melanoma patients. Cancer Immunol Res 2019;7:1162-74.

36. Böttcher JP, Bonavita E, Chakravarty P, et al. NK cells stimulate recruitment of $\mathrm{cDC} 1$ into the tumor microenvironment promoting cancer immune control. Cell 2018;172:1022-37.

37. Ishigami S, Natsugoe S, Tokuda K, et al. Prognostic value of intratumoral natural killer cells in gastric carcinoma. Cancer 2000;88:577-83.

38. Coca S, Perez-Piqueras J, Martinez D, et al. The prognostic significance of intratumoral natural killer cells in patients with colorectal carcinoma. Cancer 1997;79:2320-8.

39. Min BW, Kim WB, Kim KR, et al. The Prognostic Significance of Intratumoral Natural Killer Cells in Colorectal Cancer. Ann Surg Treat Res 2003;65:316-21.

40. Zaiatz-Bittencourt V, Finlay DK, Gardiner CM. Canonical TGF- $\beta$ signaling pathway represses human NK cell metabolism. J Immunol 2018;200:3934-41.

41. Viel S, Besson L, Marotel M, et al. Regulation of mTOR, metabolic fitness, and effector functions by cytokines in natural killer cells. Cancers 2017;9:132.

42. Viel S, Marçais A, Guimaraes FS-F, et al. TGF- $\beta$ inhibits the activation and functions of NK cells by repressing the mTOR pathway. Sci Signal 2016;9:ra19.

43. Rautela J, Dagley LF, De Oliveira CC, et al. Therapeutic blockade of activin-A improves NK cell function and antitumor immunity. Sci Signal 2019;12:eaat7527.

44. Young A, Ngiow SF, Gao Y, et al. A2AR adenosine signaling suppresses natural killer cell maturation in the tumor microenvironment. Cancer Res 2018;78:1003-16.

45. Terrén I, Orrantia A, Vitallé J, et al. NK cell metabolism and tumor microenvironment. Front Immunol 2019;10:2278

46. O'Brien KL, Finlay DK. Immunometabolism and natural killer cell responses. Nat Rev Immunol 2019;19:282-90.

47. Harmon C, Robinson MW, Hand F, et al. Lactatemediated acidification of tumor microenvironment induces apoptosis of liver-resident NK cells in colorectal liver metastasis. Cancer Immunol Res 2019;7:335-46.

48. Guerra N, Tan YX, Joncker NT, et al. NKG2D-deficient mice are defective in tumor surveillance in models of 
spontaneous malignancy. Immunity 2008;28:571-80.

49. Paczulla AM, Rothfelder K, Raffel S, et al. Absence of NKG2D ligands defines leukaemia stem cells and mediates their immune evasion. Nature 2019;572:254-9.

50. Fernández-Messina L, Ashiru O, Boutet P, et al. Differential mechanisms of shedding of the glycosylphosphatidylinositol (GPI)-anchored NKG2D ligands. J Biol Chem 2010;285:8543-51.

51. de Andrade LF, Tay RE, Pan D, et al. Antibody-mediated inhibition of MICA and MICB shedding promotes NK cell-driven tumor immunity. Science 2018;359:1537-42.

52. Hyslop SR, Josefsson EC. Undercover agents: targeting tumours with modified platelets. Trends Cancer 2017;3:235-46.

53. Gay LJ, Felding-Habermann B. Contribution of platelets to tumour metastasis. Nat Rev Cancer 2011;11:123-34.

54. Kopp H-G, Placke T, Salih HR. Platelet-derived transforming growth factor- $\beta$ down-regulates NKG2D thereby inhibiting natural killer cell antitumor reactivity. Cancer Res 2009;69:7775-83.

55. Placke T, Örgel M, Schaller M, et al. Platelet-derived MHC class I confers a pseudonormal phenotype to cancer cells that subverts the antitumor reactivity of natural killer immune cells. Cancer Res 2012;72:440-8.

56. Maurer S, Kropp KN, Klein G, et al. Plateletmediated shedding of NKG2D ligands impairs NK cell immune-surveillance of tumor cells. Oncoimmunology 2018;7:e1364827.

57. Stämpfli MR, Anderson GP. How cigarette smoke skews immune responses to promote infection, lung disease and cancer. Nat Rev Immunol 2009;9:377-84.

58. Lu LM, Zavitz CCJ, Chen B, et al. Cigarette smoke impairs NK cell-dependent tumor immune surveillance. J Immunol 2007;178:936-43.

59. Mian MF, Pek EA, Mossman KL, et al. Exposure to cigarette smoke suppresses IL-15 generation and its regulatory NK cell functions in poly I: C-augmented human PBMCs. Mol Immunol 2009;46:3108-16.

60. Mian MF, Lauzon NM, Stämpfli MR, et al. Impairment of human NK cell cytotoxic activity and cytokine release by cigarette smoke. J Leukoc Biol 2008;83:774-84.

61. Tollerud DJ, Clark JW, Brown LM, et al. Association of cigarette smoking with decreased numbers of circulating natural killer cells. Am Rev Respir Dis 1989;139:194-8.

62. Zingoni A, Fionda C, Borrelli C, et al. Natural killer cell response to chemotherapy-stressed cancer cells: role in tumor immunosurveillance. Front Immunol 2017;8:1194.

63. Markasz L, Stuber G, Vanherberghen B, et al. Effect of frequently used chemotherapeutic drugs on the cytotoxic activity of human natural killer cells. Mol Cancer Ther 2007;6:644-54.

64. Sako T, Burioka N, Yasuda K, et al. Cellular immune profile in patients with non-small cell lung cancer after weekly paclitaxel therapy. Acta Oncologica 2004;43:15-9.

65. Malmberg KJ, Carlsten M, Björklund A, et al. (eds). Natural killer cell-mediated immunosurveillance of human cancer. Elsevier, 2017.

66. Brittenden J, Heys SD, Ross J, et al. Natural killer cells and cancer. Cancer 1996;77:1226-43.

67. Senovilla L, Vacchelli E, Galon J, et al. Trial watch: Prognostic and predictive value of the immune infiltrate in cancer. Oncoimmunology 2012;1:1323-43.

68. Platonova S, Cherfils-Vicini J, Damotte D, et al. Profound coordinated alterations of intratumoral NK cell phenotype and function in lung carcinoma. Cancer Res 2011;71:5412-22.

69. Bruno A, Focaccetti C, Pagani A, et al. The proangiogenic phenotype of natural killer cells in patients with non-small cell lung cancer. Neoplasia 2013;15:133-42.

70. Al-Shibli K, Al-Saad S, Donnem T, et al. The prognostic value of intraepithelial and stromal innate immune system cells in non-small cell lung carcinoma. Histopathology 2009;55:301-12.

71. Takanami I, Takeuchi K, Giga M. The prognostic value of natural killer cell infiltration in resected pulmonary adenocarcinoma. J Thorac Cardiovasc Surg 2001;121:1058-63.

72. Villegas FR, Coca S, Villarrubia VG, et al. Prognostic significance of tumor infiltrating natural killer cells subset CD57 in patients with squamous cell lung cancer. Lung Cancer 2002;35:23-8.

73. Laughney AM, Hu J, Campbell NR, et al. Regenerative lineages and immune-mediated pruning in lung cancer metastasis. Nat Med 2020;26:259-69.

74. Jin S, Deng Y, Hao JW, et al. NK cell phenotypic modulation in lung cancer environment. PLoS One 2014;9:e109976.

75. Lavin Y, Kobayashi S, Leader A, et al. Innate immune landscape in early lung adenocarcinoma by paired singlecell analyses. Cell 2017;169:750-65.

76. Carrega P, Morandi B, Costa R, et al. Natural killer cells infiltrating human nonsmall-cell lung cancer are enriched in CD56brightCD16- cells and display an impaired capability to kill tumor cells. Cancer 2008;112:863-75.

77. Best SA, Hess J, Souza-Fonseca-Guimaraes F, et al. Harnessing natural killer immunity in metastatic small cell 
lung cancer. J Thorac Oncol 2020;15:1507-21.

78. Rudin CM, Poirier JT, Byers LA, et al. Molecular subtypes of small cell lung cancer: a synthesis of human and mouse model data. Nat Rev Cancer 2019;19:289-97.

79. Reka AK, Kurapati H, Narala VR, et al. Peroxisome proliferator-activated receptor- $\gamma$ activation inhibits tumor metastasis by antagonizing Smad3-mediated epithelial-mesenchymal transition. Mol Cancer Ther 2010;9:3221-32.

80. Liu Y, Li Y, Liu S, et al. NK cells mediate synergistic antitumor effects of combined inhibition of HDAC6 and BET in a SCLC preclinical model. Cancer Res 2018;78:3709-17.

81. Sodeur S, Ullrich S, Gustke H, et al. Increased numbers of spontaneous SCLC metastasis in absence of NK cells after subcutaneous inoculation of different SCLC cell lines into pfp/rag2 double knock out mice. Cancer Lett 2009;282:146-51.

82. Chockley PJ, Chen J, Chen G, et al. Epithelialmesenchymal transition leads to NK cell-mediated metastasis-specific immunosurveillance in lung cancer. J Clin Invest 2018;128:1384-96.

83. Best SA, De Souza DP, Kersbergen A, et al. Synergy between the KEAP1/NRF2 and PI3K pathways drives non-small-cell lung cancer with an altered immune microenvironment. Cell Metab 2018;27:935-43.

84. Schmidt L, Eskiocak B, Kohn R, et al. Enhanced adaptive immune responses in lung adenocarcinoma through natural killer cell stimulation. Proc Natl Acad Sci U S A 2019;116:17460-9.

85. Ruscetti M, Leibold J, Bott MJ, et al. NK cell-mediated cytotoxicity contributes to tumor control by a cytostatic drug combination. Science 2018;362:1416-22.

86. Keshamouni VG, Michailidis G, Grasso CS, et al. Differential protein expression profiling by iTRAQ2DLC-MS/MS of lung Cancer cells undergoing epithelial-mesenchymal transition reveals a migratory/ invasive phenotype. J Proteome Res 2006;5:1143-54.

87. Jackson EL, Willis N, Mercer K, et al. Analysis of lung tumor initiation and progression using conditional expression of oncogenic K-ras. Genes Dev 2001;15:3243-8.

88. Jackson EL, Olive KP, Tuveson DA, et al. The differential effects of mutant $\mathrm{p} 53$ alleles on advanced murine lung cancer. Cancer Res 2005;65:10280-8.

89. DuPage M, Dooley AL, Jacks T. Conditional mouse lung cancer models using adenoviral or lentiviral delivery of Cre recombinase. Nat Protoc 2009;4:1064.
90. Kang TW, Yevsa T, Woller N, et al. Senescence surveillance of pre-malignant hepatocytes limits liver cancer development. Nature 2011;479:547-51.

91. Krizhanovsky V, Yon M, Dickins RA, et al. Senescence of activated stellate cells limits liver fibrosis. Cell 2008;134:657-67.

92. Sagiv A, Biran A, Yon M, et al. Granule exocytosis mediates immune surveillance of senescent cells. Oncogene 2013;32:1971-7.

93. Coppé JP, Patil CK, Rodier F, et al. Senescence-associated secretory phenotypes reveal cell-nonautonomous functions of oncogenic RAS and the p 53 tumor suppressor. PLoS Biol 2008;6:2853-68.

94. Doyle A, Martin WJ, Funa K, et al. Markedly decreased expression of class I histocompatibility antigens, protein, and mRNA in human small-cell lung cancer. J Exp Med 1985;161:1135-51.

95. Horn L, Mansfield AS, Szczęsna A, et al. First-line atezolizumab plus chemotherapy in extensive-stage smallcell lung cancer. N Engl J Med 2018;379:2220-9.

96. Meuwissen R, Linn SC, Linnoila RI, et al. Induction of small cell lung cancer by somatic inactivation of both Trp53 and Rb1 in a conditional mouse model. Cancer Cell 2003;4:181-9.

97. Burr ML, Sparbier CE, Chan KL, et al. An evolutionarily conserved function of polycomb silences the MHC class I antigen presentation pathway and enables immune evasion in cancer. Cancer Cell 2019;36:385-401.

98. Sathe P, Delconte RB, Souza-Fonseca-Guimaraes F, et al. Innate immunodeficiency following genetic ablation of Mcl1 in natural killer cells. Nat Commun 2014;5:4539.

99. Zhu H, Blum RH, Bernareggi D, et al. Metabolic Reprograming Due to Deletion of CISH in Human Natural Killer Cells Promotes in vivo Persistence and Enhances Anti-Tumor Activity. Cell Stem Cell 2020;27:224-37.e6.

100. Delconte RB, Kolesnik TB, Dagley LF, et al. CIS is a potent checkpoint in NK cell-mediated tumor immunity. Nat Immunol 2016;17:816.

101.Cooley S, He F, Bachanova V, et al. First-in-human trial of rhIL-15 and haploidentical natural killer cell therapy for advanced acute myeloid leukemia. Blood Adv 2019;3:1970-80.

102.Wrangle JM, Velcheti V, Patel MR, et al. ALT-803, an IL-15 superagonist, in combination with nivolumab in patients with metastatic non-small cell lung cancer: a nonrandomised, open-label, phase $1 \mathrm{~b}$ trial. Lancet Oncol 2018;19:694-704. 
103. Giannelli G, Santoro A, Kelley RK, et al. Biomarkers and overall survival in patients with advanced hepatocellular carcinoma treated with TGF- $\beta$ RI inhibitor galunisertib. PLoS One 2020;15:e0222259.

104. Strauss J, Heery CR, Schlom J, et al. Phase I trial of M7824 (MSB0011359C), a bifunctional fusion protein targeting PD-L1 and TGF $\beta$, in advanced solid tumors. Clin Cancer Res 2018;24:1287-95.

105.André P, Denis C, Soulas C, et al. Anti-NKG2A mAb is a checkpoint inhibitor that promotes anti-tumor immunity by unleashing both $\mathrm{T}$ and NK cells. Cell 2018;175:1731-43.

106. Lin M, Luo H, Liang S, et al. Pembrolizumab plus allogeneic NK cells in advanced non-small cell lung cancer patients. J Clin Invest 2020;130:2560-9.

107. Tonn T, Schwabe D, Klingemann HG, et al. Treatment of patients with advanced cancer with the natural killer cell line NK-92. Cytotherapy 2013;15:1563-70.

108.Liu E, Marin D, Banerjee P, et al. Use of CAR-transduced natural killer cells in CD19-positive lymphoid tumors. N Engl J Med 2020;382:545-53.

109. Floros T, Tarhini AA, editors. Anticancer cytokines: biology and clinical effects of interferon- $\alpha 2$, interleukin (IL)-2, IL-15, IL-21, and IL-12. Elsevier, 2015.

110.Ito S, Bollard CM, Carlsten M, et al. Ultra-low dose interleukin-2 promotes immune-modulating function of regulatory $\mathrm{T}$ cells and natural killer cells in healthy volunteers. Mol Ther 2014;22:1388-95.

111.Dranoff G. Cytokines in cancer pathogenesis and cancer therapy. Nat Rev Cancer 2004;4:11-22.

112. Sim GC, Liu C, Wang E, et al. IL2 variant circumvents ICOS+ regulatory T-cell expansion and promotes NK cell activation. Cancer Immunol Res 2016;4:983-94.

113.Levin AM, Bates DL, Ring AM, et al. Exploiting a natural conformational switch to engineer an interleukin-2 'superkine'. Nature 2012;484:529-33.

114. Ghasemi R, Lazear E, Wang X, et al. Selective targeting of IL-2 to NKG2D bearing cells for improved immunotherapy. Nat Commun 2016;7:12878.

115. Rautela J, Huntington ND. IL-15 signaling in NK cell cancer immunotherapy. Curr Opin Immunol 2017;44:1-6.

116. Rubinstein MP, Kovar M, Purton JF, et al. Converting IL15 to a superagonist by binding to soluble IL-15R $\alpha$. Proc Natl Acad Sci U S A 2006;103:9166-71.

117. Romee R, Cooley S, Berrien-Elliott MM, et al. First-inhuman phase 1 clinical study of the IL-15 superagonist complex ALT-803 to treat relapse after transplantation. Blood 2018;131:2515-27.
118.Soiffer RJ, Davids MS, Chen YB. Tyrosine kinase inhibitors and immune checkpoint blockade in allogeneic hematopoietic cell transplantation. Blood 2018;131:1073-80.

119. Herbertz S, Sawyer JS, Stauber AJ, et al. Clinical development of galunisertib (LY2157299 monohydrate), a small molecule inhibitor of transforming growth factor-beta signaling pathway. Drug Des Devel Ther 2015;9:4479.

120. Yingling JM, McMillen WT, Yan L, et al. Preclinical assessment of galunisertib (LY2157299 monohydrate), a first-in-class transforming growth factor- $\beta$ receptor type I inhibitor. Oncotarget 2018;9:6659.

121.Faivre S, Santoro A, Kelley RK, et al. Novel transforming growth factor beta receptor I kinase inhibitor galunisertib (LY2157299) in advanced hepatocellular carcinoma. Liver Int 2019;39:1468-77.

122. Knudson KM, Hicks KC, Luo X, et al. M7824, a novel bifunctional anti-PD-L1/TGF $\beta$ Trap fusion protein, promotes anti-tumor efficacy as monotherapy and in combination with vaccine. Oncoimmunology 2018;7:e1426519.

123.Lan Y, Zhang D, Xu C, et al. Enhanced preclinical antitumor activity of $\mathrm{M} 7824$, a bifunctional fusion protein simultaneously targeting PD-L1 and TGF- $\beta$. Sci Transl Med 2018;10:eaan5488.

124. Mazzaschi G, Facchinetti F, Missale G, et al. The circulating pool of functionally competent $\mathrm{NK}$ and CD8+ cells predicts the outcome of anti-PD1 treatment in advanced NSCLC. Lung Cancer 2019;127:153-63.

125.Zemek RM, De Jong E, Chin WL, et al. Sensitization to immune checkpoint blockade through activation of a STAT1/NK axis in the tumor microenvironment. Sci Transl Med 2019;11:eaav7816.

126. Segal NH, Naidoo J, Curigliano G, et al. First-in-human dose escalation of monalizumab plus durvalumab, with expansion in patients with metastatic microsatellite-stable colorectal cancer. J Clin Oncol 2018;36:3540.

127.Leung $W$. Infusions of allogeneic natural killer cells as cancer therapy. Clin Cancer Res 2014;20:3390-400.

128. Parkhurst MR, Riley JP, Dudley ME, et al. Adoptive transfer of autologous natural killer cells leads to high levels of circulating natural killer cells but does not mediate tumor regression. Clin Cancer Res 2011;17:6287-97.

129. Yang YJ, Park JC, Kim HK, et al. A trial of autologous ex vivo-expanded NK cell-enriched lymphocytes with docetaxel in patients with advanced non-small cell lung 
cancer as second-or third-line treatment: phase IIa study. Anticancer Res 2013;33:2115-22.

130. Bachanova V, Miller JS. NK cells in therapy of cancer. Crit Rev Oncog 2014;19:133-41.

131. Ruggeri L, Capanni M, Urbani E, et al. Effectiveness of donor natural killer cell alloreactivity in mismatched hematopoietic transplants. Science 2002;295:2097-100.

132. Guillerey C, Huntington ND, Smyth MJ. Targeting natural killer cells in cancer immunotherapy. Nat Immunol 2016;17:1025.

133. Cheng M, Chen Y, Xiao W, et al. NK cell-based immunotherapy for malignant diseases. Cell Mol Immunol 2013;10:230-52.

134. Gong JH, Maki G, Klingemann HG. Characterization of a human cell line (NK-92) with phenotypical and functional characteristics of activated natural killer cells. Leukemia 1994;8:652-8.

Cite this article as: Hess JB, Sutherland KD, Best SA. Exploring natural killer cell immunology as a therapeutic strategy in lung cancer. Transl Lung Cancer Res 2021;10(6):2788-2805. doi: 10.21037/tlcr-20-765
135. Tam YK, Miyagawa B, Ho VC, et al. Immunotherapy of malignant melanoma in a SCID mouse model using the highly cytotoxic natural killer cell line NK-92.J Hematother 1999;8:281-90.

136. Yan Y, Steinherz P, Klingemann H-G, et al. Antileukemia activity of a natural killer cell line against human leukemias. Clin Cancer Res 1998;4:2859-68.

137. Arai S, Meagher R, Swearingen M, et al. Infusion of the allogeneic cell line NK-92 in patients with advanced renal cell cancer or melanoma: a phase I trial. Cytotherapy 2008;10:625-32.

138. Klingemann H, Boissel L, Toneguzzo F. Natural killer cells for immunotherapy-advantages of the NK-92 cell line over blood NK cells. Front Immunol 2016;7:91.

139. Rafiq S, Hackett CS, Brentjens RJ. Engineering strategies to overcome the current roadblocks in CAR T cell therapy. Nat Rev Clin Oncol 2020;17:147-67. 